\title{
CRITÉRIOS DE RARIDADE BIBLIOGRÁFICA: PROBLEMAS, METODOLOGIAS E APLICAÇÕES
}

\author{
HEYTOR DINIZ TEIXEIRA* \\ NAILLÊ DE MORAES GARCIA* \\ MARCIA CARVALHO RODRIGUES ${ }^{* * *}$
}

\begin{abstract}
RESUMO
O presente trabalho é resultado de uma revisão teórica sobre o conceito de raridade bibliográfica. Apresenta a importância da criação e adoção de critérios de raridade bibliográfica como elementos norteadores do trabalho biblioteconômico. Expõe, ainda, os critérios de raridade adotados por duas instituições brasileiras: a Biblioteca Nacional (Rio de Janeiro, RJ) e a Biblioteca Rio-Grandense (Rio Grande, RS). O estudo conclui que ambas instituições adotam critérios semelhantes. Considera, ainda, a presença de lacunas nas práticas profissionais dos bibliotecários curadores de acervos raros. Acredita-se, contudo, que seja possível modificar essa realidade com a adoção de uma formação profissional mais humanista.
\end{abstract}

PALAVRAS-CHAVE: Raridade bibliográfica. Livros raros. Biblioteca Nacional. Biblioteca Rio-Grandense.

\begin{abstract}
The present work is the result of a theoretical revision about the concept of bibliographic rarity. It presents the importance of the creation and adoption of criteria of bibliographic rarity as guiding elements of library work. It also shows the rarity criteria adopted by two brazilian institutions: the National Library (Rio de Janeiro, RJ) and the Rio-Grandense Library (Rio Grande, RS). The study concludes that both institutions adopt similar criteria. It also considers the presence of gaps in the professional practices of librarians who curate rare collections. However, we believe that it is possible to change this reality with the adoption of a more humanistic professional formation.
\end{abstract}

KEYWORDS: Bibliographic rarity. Rare books. National Library. Rio-Grandense Library.

\footnotetext{
* Acadêmico do Curso de Bacharelado em Biblioteconomia da Universidade Federal do Rio Grande (FURG). E-mail: dinizheytor@gmail.com.

* Acadêmica do Curso de Bacharelado em Biblioteconomia da Universidade Federal do Rio Grande (FURG). E-mail: naille.moraes@gmail.com.

*** Docente do Curso de Bacharelado em Biblioteconomia da Universidade Federal do Rio Grande (FURG). Doutora em Memória Social e Patrimônio Cultural (UFPel). E-mail: marciarodriguesfurg@gmail.com.
} 


\section{INTRODUÇÃO}

O livro, desde o seu surgimento, apresenta como principal função registrar o conhecimento humano e, por meio de suas páginas, levar informações às gerações vindouras. $\mathrm{O}$ artefato livro remete à ideia de conhecimento, intelecto, cultura, erudição. Enquanto objeto cultural, carrega em si essa simbologia e agrega, a quem o possui, um status de poder, influência e sabedoria.

No decorrer da sua história, o livro passou por uma série de modificações, tanto de forma (rolo, códice, hipertexto), quanto de suporte (madeira, pergaminho, papel, suportes eletrônicos etc.), e a sua evolução é percebida por estudiosos da área da Biblioteconomia de livros raros, atentos à relevância das obras bibliográficas para os estudos da história do ser humano. Diante da importância histórica, cultural e patrimonial destes materiais, busca-se, por meio da realização de revisão teórica sobre o tema proposto, abordar a pertinência da aplicação de critérios de raridade bibliográfica internacionalmente aceitos para a identificação de obras em uma coleção, tendo como objetivo principal salvaguardar a memória social.

Os critérios de raridade bibliográfica não são elementos tidos como verdadeiros ou falsos. De acordo com Araujo (2015), tratam-se, apenas, de construções baseadas no aporte teórico da área da Biblioteconomia de livros raros que fundamentam a prática dos bibliotecários que gerenciam esse tipo de acervo.

A aplicação do termo "raro" a uma obra bibliográfica é subjetiva por diferentes razões e motivações. Distante de se ter uma definição objetiva, a área da Biblioteconomia de livros raros, no intuito de nortear estudiosos e profissionais que lidam diretamente com este tipo de acervo, defende a adoção de critérios de raridade para a identificação de obras raras em meio a coleções gerais de bibliotecas.

De maneira geral, os critérios utilizados pelas bibliotecas brasileiras têm origem nos critérios da Biblioteca Nacional (BN). Percebe-se, ainda, que alguns dos critérios utilizados pela BN são compartilhados por muitas bibliotecas nacionais de diversos países. Indo mais a fundo na origem de alguns destes critérios, observa-se que estes se originam de parâmetros adotados por bibliófilos e livreiros especializados no comércio de livros raros.

Levando em consideração o exposto, esta pesquisa, além de buscar averiguar a importância da adoção de critérios de raridade para identificar tais obras em meio às coleções de bibliotecas, apresenta, ainda, os critérios definidos pela BN e pela Biblioteca Rio-Grandense, localizada na cidade do Rio Grande, RS. 


\section{A IMPORTÂNCIA DA ELABORAÇÃO DE CRITÉRIOS DE RARIDADE BIBLIOGRÁFICA}

Critérios de raridade bibliográfica são elaborados e adotados para balizar as bibliotecas e seus profissionais no processo de identificação de obras raras. Dentre os diversos critérios de raridade adotados pelas bibliotecas, há os que são universalmente aceitos e os circunstanciais. Como critérios universalmente aceitos podemos citar, por exemplo, os incunábulos e os manuscritos. Já como critérios de raridade de caráter circunstancial, podemos citar, por exemplo, livros que foram impressos dentro de um determinado período, em uma determinada localidade, levando em consideração o surgimento da tipografia nesta localidade. Ou, ainda, obras que pertenceram a uma personalidade de destaque para uma determinada instituição - tais materiais poderiam, talvez, não ter a mesma importância para outra instituição (daí a relatividade do critério).

É, portanto, possível criar critérios além dos universalmente aceitos, de maneira a atender às reais necessidades das bibliotecas, considerando as suas particularidades. Diante de tal fato, para Pinheiro (1989, p. 21), ao elaborar critérios de raridade bibliográfica, deve-se buscar

[...] estabelecer critérios para enfoque de raridade/preciosidade bibliográfica, não universais, mas aceitos universalmente; e associar ao caráter de unicidade, atribuído ao livro, características tais como: beleza tipográfica; edições limitadas, numeradas ou personalizadas; limite histórico, definido pelas características artesanais.

Daí resulta, portanto, a dificuldade em estabelecer uma definição para livro raro. Para Pinheiro (2009), o livro raro é o único item conhecido de uma determinada obra, ou porque é precioso para alguém, ou porque é inquestionavelmente raro. Há uma subjetividade na definição de raridade aplicada ao livro, pois além de estar ligada à realidade, à intencionalidade e aos objetivos de cada biblioteca e da instituição a que pertence, também está diretamente relacionada à bagagem cultural do curador do acervo.

Além disso, a constatação da importância dos conteúdos das obras pode variar de acordo com o local e o tempo. Obras de grande importância no Brasil, por exemplo, podem não ter a mesma relevância verificada em outros países, porque seu valor depende de conhecimentos relativos ao contexto local. Também, com o passar do tempo e em decorrência da realização de pesquisas, poderão ocorrer 
mudanças na valoração de certas obras, e até mesmo passar a ser considerada rara alguma obra que antes era tida como comum. Segundo Galbraith e Smith (2012, p. 3, tradução nossa),

É difícil demarcar exatamente quando o livro raro, em oposição a um livro comum, tornou-se um conceito distinto; de fato, hoje, definir livros raros, permanece variável, porque livros que antes eram considerados comuns adquirem novo significado quando novas áreas de pesquisa, como estudos sobre alfabetização e história do livro, são praticados pela comunidade acadêmica. ${ }^{1}$

Existem diferentes interpretações sobre raridade bibliográfica. Para o mercado livreiro antiquário, por exemplo, a importância do livro está no próprio objeto e suas especificidades: o livro é visto como artefato. $O$ valor de mercado se sobressai em relação aos demais critérios. Dessa forma, quanto menos exemplares existirem, mais valioso será o livro. Outro fator que influencia o encarecimento de um livro raro é a procura pelo item. Igualmente, o estado de conservação é determinante para valorizar um exemplar. A raridade, então, não se aplica à obra como um todo, mas a determinado(s) exemplar(es).

Diferentemente, para as bibliotecas, os aspectos histórico e cultural do livro importam mais do que seu valor de mercado, e o estado de conservação, apesar de importante, não é determinante para qualificar um exemplar como raro. A relevância da definição e tratamento das obras raras, nesse caso, tem o sentido de conservação do patrimônio cultural e histórico, por isso o critério de antiguidade acaba sendo um dos mais utilizados. A esse respeito, afirma Rodrigues (2006, p. 115):

O critério de raridade adotado pelas bibliotecas geralmente está vinculado à idéia de antigüidade e valor histórico-cultural. $A$ idade cronológica leva em conta a aparição da imprensa nos diversos lugares do mundo e/ou na região onde foram impressas as obras e, desta forma, justifica o princípio de que todos os livros publicados artesanalmente merecem ser considerados raros.

A elaboração de critérios de raridade contribui para objetivar algo tão subjetivo: retira-se a dependência da identificação destas

\footnotetext{
1 "It is difficult to demarcate exactly when the rare book as opposed to a commom book became a distinctive concept; indeed, defining rare books today remains variable because books that were previously considered common acquire new significance when new areas of research, such as literacy studies and book history, are practiced by the scholarly community." (GALBRAITH; SMITH, 2012, p. 3)
} 
obras apenas dos conhecimentos e bagagem cultural dos indivíduos responsáveis por tais acervos. Assim, salvaguardam-se os livros raros, tidos como elementos da memória cultural de um determinado local, povo ou instituição. Com a consulta a esses critérios, é possível identificar as obras raras mesmo diante das diferentes circunstâncias. Pinheiro (2015, p. 34), ainda afirma que

\begin{abstract}
Um caminho para escapar à dependência imposta pela subjetividade conceitual, que atribui aquela função a uma autoridade reconhecida, mas que nem sempre formaliza seus critérios, é a busca por critérios próprios de raridade que revelem a missão institucional e a formação e o desenvolvimento da coleção, no presente e no futuro.
\end{abstract}

Para isso, seria imprescindível o trabalho conjunto de um grupo de profissionais de diversas áreas e com diferentes competências para analisar e verificar e a raridade do livro, pois nem sempre o bibliotecário, sozinho, poderá analisar com precisão obras de áreas específicas, que possuem valor intrínseco em seu próprio escopo, mas que poderão parecer comuns aos olhos leigos. Dessa forma, apesar da subjetividade do termo raridade, por meio da realização de um trabalho multidisciplinar, torna-se possível a verificação do valor intersubjetivo das obras. Segundo Andrade e Cantalino (2003, p. 8),

Dizer algo sobre a raridade de um livro não é afirmar nada que possa ser verificado como verdade, contudo, não deixa de ter sentido e importância a afirmação do valor de raridade. Não sendo uma realidade objetiva e verificável é, entretanto, um juízo de valor intersubjetivo, mediado no plano da linguagem. Portanto um juízo público.

A raridade bibliográfica é um tema bastante discutido na área da Biblioteconomia de livros raros, contudo, é um campo onde há certo cuidado na definição universal de um conceito de raro em razão da sua relatividade. O tempo, os aspectos bibliológicos, 0 local de produção da obra, dentre outros fatores, tornam subjetiva a definição de "livro raro". Segundo Silva e Laine (1990 apud FROES, 1995, p. 33),

A raridade não é um termo absoluto, invariável e de grau constante, devendo ser relativa aos países e regiões. [...] Alguns critérios são indiscutíveis: os incunábulos, as edições princeps dos clássicos, a primeira produção tipográfica de uma determinada área geográfica e obras com tiragens reduzidas. 
Assim, diante dessas diferenças, faz-se necessária a elaboração de critérios que se tornem guias para as bibliotecas no processo de identificação de livros raros em meio a seus acervos.

\subsection{Critérios de raridade: fundamentos para a sua elaboração}

Pinheiro (1989), em seu livro "O que é livro raro", apresenta uma proposta metodológica para a elaboração de critérios de raridade, a qual leva em consideração cinco aspectos determinantes para a sua construção. São eles: limite histórico, aspectos bibliológicos, valor cultural, pesquisa bibliográfica e características do exemplar.

Por limite histórico, entende-se o período em que a obra foi produzida, considerando o ano da invenção da imprensa, mas, principalmente, o período em que se iniciou a fase dos impressos na localidade onde a obra foi produzida, se a produção apresenta, ainda, características artesanais, dentre outros fatores. Segundo Pinheiro (2009, p. 34),

A história cronológica do livro configura-se, então, como critério. A avaliação de um livro pela data de publicação tem sido considerada como um dos "métodos" mais seguros para sua qualificação como raro. Os catálogos de livros "raros" publicados destacam a data de publicação como o primeiro e, muitas vezes, o único critério de raridade, levando à valorização da idade da obra.

Os aspectos bibliológicos correspondem à materialidade do livro. As características atribuem valor ao livro como objeto porque este é visto como investimento, relíquia e/ou símbolo de status.

O valor cultural diz respeito às características estruturais do livro, suas origens e singularidades, ou assunto.

A pesquisa bibliográfica faz uso de fontes de informação de reconhecida importância para a área da Biblioteconomia de livros raros. Tais fontes indicam unicidade e raridade da obra, preciosidade e celebridade e, também, curiosidade.

As características do exemplar dizem respeito aos elementos acrescentados após a sua publicação, como marcas de propriedade e procedência, marcas de artífices e comerciantes renomados, marcas de leitura, dedicatórias, etc.

As obras raras são, assim, definidas por diferentes razões. São, muitas vezes, detentoras de informações que dificilmente serão encontradas em outros exemplares, são de difícil acesso, são 
valiosas. Por isso, uma vez perdidas, a sua reposição seria uma tarefa praticamente impossível. Por essa razão, esse tipo de acervo requer cuidados especiais em relação ao seu tratamento.

\subsection{Critérios adotados pela Biblioteca Nacional}

A Fundação Biblioteca Nacional (FBN), como unidade de informação referência no país em vários campos da Biblioteconomia, utiliza-se de critérios internacionalmente aceitos para a identificação de livros raros e fornece as orientações às bibliotecas pertencentes a outras instituições.

Através do Plano Nacional de Recuperação de Obras Raras (PLANOR), desde 1983, a FBN tem como objetivo a identificação e a recuperação das obras raras existentes não só na Biblioteca Nacional (BN), mas em todo o território nacional, servindo como um guia para as bibliotecas brasileiras.

Para a definição de critérios que fazem parte da metodologia de identificação de obras raras, é necessária a presença de uma comissão de profissionais de áreas multidisciplinares, para trabalharem em conjunto. Dentre esses profissionais, encontram-se os bibliotecários, que possuem os conhecimentos técnicos, teóricos e bibliográficos; os próprios usuários, que possuem o conhecimento das obras que são referências em cada área do conhecimento; e os gestores da instituição, que possuem o conhecimento histórico administrativo. Segundo Pinheiro (1989, p. 21-22),

A análise desses critérios deve ser realizada, no mínimo, sob uma das seguintes perspectivas: a) a do bibliotecário, em face de um acervo considerado antigo; b) a do gerente da instituição, perante um acervo que desconhece e considera "valioso", por contribuir parte da história da instituição; e c) a do usuário, que sintetiza as perspectivas anteriores.

A BN estabeleceu seus próprios critérios e estes, até o momento, têm sido utilizados como referências por outras instituições do país. Em 2012, durante o $16^{\circ}$ Curso Informativo Sobre Preservação de Acervos, o PLANOR divulgou uma ordem de serviço oficial, do ano de 1984, assinada pela diretora da época, Maria Alice Barroso, que determinada a finalidade, os princípios e definições norteadoras para o estabelecimento de critérios para a qualificação de obras raras.

De acordo com o documento, a finalidade para a delimitação dos critérios empregados na qualificação das obras raras serve para o 
aperfeiçoamento dos serviços da biblioteca. Dentre os critérios, encontram-se: a) todas as impressões dos séculos XV, XVI e XVII; b) impressões do século XVIII até 1720; c) obras editadas no Brasil até 1841; d) edições de tiragens reduzidas; e) edições especiais, de luxo, para bibliófilos; f) edições clandestinas; g) obras esgotadas; h) exemplares de coleções especiais, em geral com belas encadernações e "ex-libris"; i) exemplares com anotações manuscritas de importância, incluindo-se dedicatórias (PLANOR, 2012).

Diante dos critérios de raridade utilizados pela $B N$, ainda pode haver questionamentos por parte das instituições sobre a importância da sua utilização, tendo em vista a idade cronológica da obra. Segundo Rodrigues (2006, p. 115),

Torna-se necessário, portanto, sistematizar uma metodologia a fim de explicitar e justificar os critérios para identificar livros raros dentro de uma coleção. $O$ uso de critérios de raridade bibliográfica justifica-se pelo fato de que tais livros merecem tratamento diferenciado, visto seu valor histórico, cultural, monetário, e mesmo a dificuldade em obterem-se exemplares.

Apesar da idade ser um dos fatores determinantes, o livro precisa se enquadrar em um ou mais critérios para determinar-se que ele é raro. Além disso, Pinheiro (1989) atenta que uma das recomendações metodológicas para a definição dos critérios são os aspectos bibliológicos de cada volume, ou seja, se eles apresentam beleza tipográfica, quais materiais foram utilizados como suporte da impressão, o tipo de papel, dentre outros.

A necessidade da criação, formalização e utilização dos critérios de raridade vem da importância de salvaguardar todo esse acervo raro, que contém uma parcela da história cultural, política e social de uma época, localidade e/ou instituição.

\section{BIBLIOTECA RIO-GRANDENSE: ACERVO RARO E CRITÉRIOS DE RARIDADE}

Apesar da sua localização geográfica, a cidade do Rio Grande (Rio Grande do Sul, Brasil) nunca se isolou do restante o país no que se refere à cultura e aos acontecimentos ao redor do mundo no decorrer dos anos. Segundo Vieira e Jaeger (1979, p. 88), 
As circunstâncias ditadas pela localização geográfica da cidade impunham aos grandes negociantes um acompanhamento do que se passava no mundo político e cultural das metrópoles. O grande caminho de contato, rápido e permanente, representado pelo oceano, evitava o isolamento e o confinamento cultural dos negociantes.

FIGURA 1 - Mapa da localização da Biblioteca Rio-Grandense.

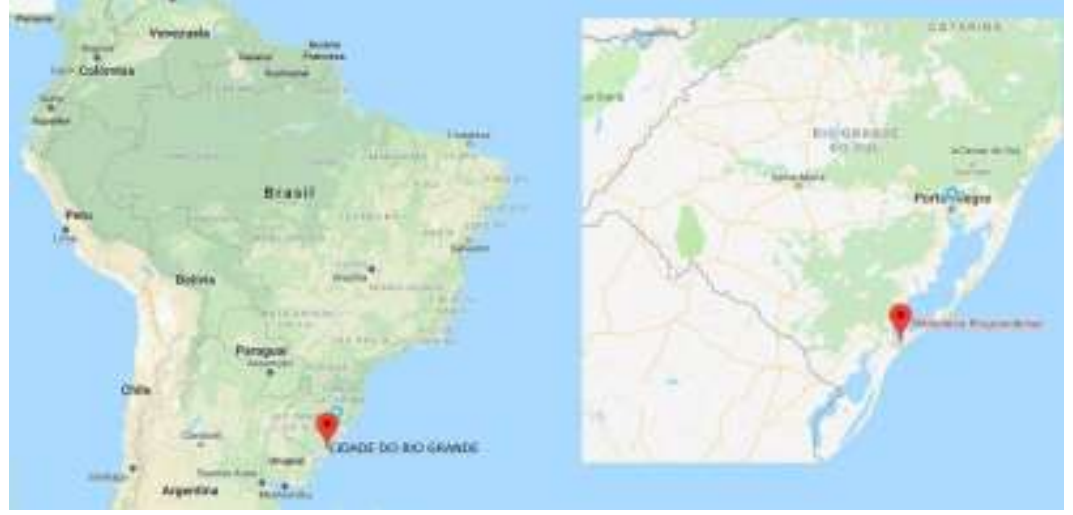

FONTE: Adaptado de Google Maps (2018).

Desde que foi fundada, em 1846, a Biblioteca Rio-Grandense é procurada por pesquisadores de todas as localidades do mundo. Sendo uma instituição de direito privado, mantida principalmente por meio das mensalidades dos sócios, os recursos financeiros são escassos. Nesse sentido, é imprescindível que sejam realizados convênios e projetos para que sejam empregadas novas práticas e pesquisas no local.

Em janeiro de 1977, firmou-se um convênio de colaboração mútua entre a Biblioteca Rio-Grandense e a Universidade Federal do Rio Grande (FURG). As prioridades desse convênio foram: o processamento técnico das obras raras e/ou valiosas, das obras de Direito e do acervo de fotografias antigas (VIEIRA; JAEGER, 1979).

A partir desse convênio, um grupo de professoras e alunas do curso de Biblioteconomia da FURG realizou um estudo sobre as obras lá depositadas. De acordo com Vieira e Jaeger (1979) a biblioteca possuía, no final da década de 1970, um acervo com cerca de 210.000 volumes, dentre os quais encontravam-se 750 exemplares de obras raras e/ou valiosas.

No que se refere ao tratamento direcionado às obras raras, Vieira e Jaeger (1979) afirmam que estas foram retiradas do acervo 
geral, sendo selecionadas por século, depois organizadas por autor e título dentro de cada século, e em seguida postas em uma sala adequada: a Sala Dr. Joaquim da Silva Filho.

Quanto à metodologia utilizada para a identificação dessas obras, foi empreendida uma análise minuciosa das mesmas, além de terem sido consultados especialistas na área. Vieira e Jaeger (1978, p. 61), descrevem quais critérios foram empregados:

A primeira tarefa desenvolvida no trato de tão substancial acervo foi o de catalogar as obras consideradas raras e ou preciosas. Adotouse como primeiro critério a separação de obras antigas, para, depois, estabelecer uma segunda separação levando-se em conta: ano de publicação, editora, aspectos gráficos, idioma, auspícios da publicação e conteúdo.

Atualmente, os critérios da $\mathrm{BN}$ vêm sendo utilizados como instrumentos de pesquisa para a identificação de obras raras na Biblioteca Rio-Grandense. Além disso, os responsáveis pelo acervo são profissionais bibliotecários e possuem o conhecimento necessário para o tratamento deste acervo, reconhecendo a sua importância para pesquisa.

Apesar disso, a curadoria destas obras não é feita de maneira preventiva, colocando em risco a vida útil do acervo. Principalmente pela falta de investimentos, as atividades biblioteconômicas voltadas às obras raras na Biblioteca Rio-Grandense, atualmente, são precárias, sendo necessária uma ação visando o resguardo das obras no local, com o intuito de salvaguardar a memória cultural.

\section{CONCLUSÕES}

Apesar da dificuldade de estabelecer critérios objetivos para a identificação de obras raras, tanto pela subjetividade envolvida no momento de avaliação, quanto na relatividade do próprio termo "raridade", é imprescindível que seja adotada uma metodologia que possa ser aplicada para a definição de livros raros. Sua importância reside principalmente na preservação do patrimônio histórico e cultural da humanidade e, também, na garantia de acesso a essas informações.

A partir deste estudo, chegou-se aos principais aspectos a serem considerados no momento de aplicar a metodologia proposta por Pinheiro (1989): o limite histórico, os aspectos bibliológicos, o valor cultural, a pesquisa bibliográfica e as características do exemplar. 
A BN adota critérios aceitos internacionalmente e fornece as orientações para bibliotecas de outras instituições. A exemplo disso, verifica-se que, apesar das dificuldades enfrentadas, a Biblioteca Rio-Grandense possui um grande número de obras de suma importância e segue as indicações da BN para a verificação da raridade bibliográfica.

Atualmente, percebe-se que os cursos de Biblioteconomia brasileiros, em sua maioria, apresentam uma formação voltada nas e para as tecnologias, na administração dos novos formatos da informação e nas unidades informacionais pelas quais esses profissionais serão responsáveis. A Biblioteconomia de livros raros ficou em segundo plano, viabilizando o desinteresse da comunidade pelo desenvolvimento de pesquisas sobre o tema. Levando em conta a importância dos acervos bibliográficos raros, julga-se importante que os estudantes de Biblioteconomia tenham uma formação não somente tecnicista e voltada para as tecnologias, mas também direcionada para o viés cultural da área.

Os futuros profissionais da informação precisam ter condições teóricas para fundamentar sua prática profissional. Isso será possível através de uma formação acadêmica mais humanista. A memória cultural presente nas obras raras não pode se perder devido ao despreparo dos profissionais, afinal, uma parte da história e da identidade cultural dos povos está contida nelas.

\section{REFERÊNCIAS}

ANDRADE, R. H. R. de; CANTALINO, M. das G. N. A raridade como questão epistemológica e política: um novo paradigma para os curadores de acervos especiais. Anais da Biblioteca Nacional, Rio de Janeiro, v.123, p.49-58, 2003. Disponivel em: <https://goo.gl/Hj41SU>. Acesso em: 16 nov. 2017.

ARAUJO, A. V. F. Gestão de coleções especiais no séc. XXI: conceitos, problemas, ações. In: VIEIRA, B. V. G.; ALVES, A. P. M. (Org.). Acervos especiais: memórias e diálogos. São Paulo: Cultura Acadêmica, 2015. p. 15-32. Disponível em: <https://goo.gl/syFi2J>. Acesso em: 16 nov. 2017.

FROES, R. C. Obras raras no Brasil: estudo dos critérios de raridade bibliográfica, tratamento técnico e preservação das coleções. 1995. Dissertação (Mestrado) - Universidade Federal de Minas Gerais, Mestrado em Ciência da Informação, Belo Horizonte, 1995. Disponível em: <https://goo.gl/FaMnJv>. Acesso em: 16 nov. 2017.

GALBRAITH, S. K.; SMITH, G. D. Rare book librarianship: an introduction and guide. Santa Barbara: ABC-CLIO, 2012.

GOOGLE MAPS. [S.I.], 2018. Disponível em: <https://goo.gl/mJE76D>. Acesso 
em: 06 ago. 2018.

PINHEIRO, A. V. História, memória e patrimônio: convergências para o futuro dos acervos especiais. In: VIEIRA, B. V. G.; ALVES, A. P. M. (Org.). Acervos especiais: memórias e diálogos. São Paulo: Cultura Acadêmica, 2015. p. 33-44. Disponível em: <https://goo.gl/syFi2J>. Acesso em: 16 nov. 2017.

. Livro raro: antecedentes, propósitos e definições. In: SILVA, H. C.; BARROS, M. H. T. C. (Org.). Ciência da Informação: múltiplos diálogos. Marília, SP: Oficina universitária, 2009. p. 31-44. Disponível em: <https://goo.gl/5hdVM3>. Acesso em: 17 nov. 2017.

. Que é livro raro? Uma metodologia para o estabelecimento de critérios de raridade bibliográfica. Rio de Janeiro: Presença, 1989.

PLANOR. Plano Nacional de Recuperação de Obras Raras. Rio de Janeiro, [2018]. Disponível em: <https://goo.gl/ZjTEUL>. Acesso em 08 nov. 2017.

PLANOR. $16^{\circ}$ Curso Informativo Sobre Preservação de Acervos. Rio de Janeiro, [2012]. Disponível em: <https://goo.gl/6XJM3U>. Acesso em 08 nov. 2017.

RODRIGUES, M. C. Como definir e identificar obras raras? Critérios adotados pela Biblioteca Central da Universidade de Caxias do Sul. Ciência da Informação, Brasília, v. 35, n. 1, p. 115-121, 2006. Disponível em: <https://goo.gl/ffG2ww>. Acesso em: 06 ago. 2018.

VIEIRA, C. M.; JAEGER, L. G. Levantamento bibliográfico de obras raras e/ou preciosas. Revista do Departamento de Biblioteconomia e História, Rio Grande, v. 1, n. 1, p. 60-64, 1978.

Processamento técnico do valioso acervo de fotografias da centenária Biblioteca Rio-Grandense. Revista do Departamento de Biblioteconomia e História, Rio Grande, v. 1, n. 3, p. 87-98, 1979. 